\title{
Effect of conventional TENS on pain and electromyographic activity of masticatory muscles in TMD patients
}

\section{Efeito da TENS convencional sobre a dor e a atividade eletromiográfica dos músculos mastigatórios em pacientes com DTM}

\author{
Delaine Rodrigues* \\ Anamaria Oliveira Siriani** \\ Fausto Bérzin $* * *$
}

\begin{abstract}
Temporomandibular disorders (TMD) are characterized by several signs and symptoms, such as pain and changes in the electrical activity of masticatory muscles. Considering that transcutaneous electrical nerve stimulation (TENS) is a resource indicated to promote analgesia, the objective of this study was to evaluate the effect of TENS on pain and electromyographic (EMG) activity of the jaw elevator muscles in TMD patients. This study evaluated 35 female volunteers: 19 TMD patients (mean age $=23.04 \pm 3.5$ ) and 16 normal subjects (mean age $=23.3 \pm 3.0$ ). Transcutaneous electrical nerve stimulation (conventional mode, $150 \mathrm{~Hz}$ ) was applied once to each group for 45 minutes. Surface electromyography (gain of 100 times and $1 \mathrm{kHz}$ sampling frequency) and the visual analogue scale (VAS) were applied before and immediately after TENS application. Both VAS data and root mean square (RMS) values were analyzed using Student's $t$-test. The TMD group, compared to the control group, showed higher EMG activity of the jaw elevator muscles at rest. No difference was observed between the groups regarding maximum voluntary clenching (MVC). In TMD patients, TENS reduced both pain and EMG activity of the anterior portion of the temporal muscle, increasing the activity of the masseter muscles during MVC. It is possible to conclude that a single TENS application is effective in pain reduction. However, it does not act homogeneously on the features of the electric activity of the muscles evaluated.
\end{abstract}

DESCRIPTORS: Temporomandibular joint; Electromyography; Masticatory muscles; Transcutaneous electric nerve stimulation; Facial pain.

RESUMO: A desordem temporomandibular (DTM) é caracterizada por diversos sinais e sintomas, como dor e alteração do sinal eletromiográfico dos músculos da mastigação. Considerando que a estimulação elétrica nervosa transcutânea (TENS) é um recurso indicado para promover analgesia, o objetivo deste trabalho foi avaliar o efeito da TENS na dor e na atividade eletromiográfica (EMG) dos músculos elevadores da mandíbula em indivíduos com DTM. Foram selecionados 35 voluntários do sexo feminino, 19 portadores de DTM (média de 23,04 anos $\pm 3,5$ ) e 16 normais (média de 23,3 anos $\pm 3,0$ ). A TENS (modo convencional, $150 \mathrm{~Hz}$ ) foi aplicada uma vez em ambos os grupos, por $45 \mathrm{~min}$. O exame EMG de superficie (ganho de 100 vezes e freqüência de amostragem de $1 \mathrm{kHz}$ ) e a escala visual analógica (EVA) foram realizados antes e imediatamente depois da aplicação da TENS. Os dados da EVA e os valores da "root mean square" (RMS) foram analisados pelo teste $t$ de Student. Observou-se que, na situação de repouso, os indivíduos com DTM apresentam um aumento da atividade EMG dos músculos elevadores da mandíbula em relação aos do grupo controle. Na contração voluntária máxima (CVM), não foram observadas diferenças entre os grupos. Nos portadores de DTM, a TENS reduziu a dor, a atividade EMG da porção anterior do músculo temporal e aumentou a atividade dos músculos masseteres durante a CVM. É possível concluir que apenas uma aplicação da TENS é efetiva para reduzir a dor, porém não atua de forma homogênea sobre as características da atividade elétrica dos músculos avaliados.

DESCRITORES: Articulação temporomandibular; Eletromiografia; Músculos mastigatórios; Estimulação elétrica transcutânea do nervo; Dor facial.

\section{INTRODUCTION}

Temporomandibular disorders (TMD) are characterized by several symptoms and clinical signs, such as pain in the temporomandibular joint and/or masticatory muscles, and changes

\footnotetext{
* PhD, Professor, Undergraduate and Graduate Courses in Physiotherapy, Methodist University of Piracicaba.

** PhD, Professor, Graduate Course in Orthopedics, Traumatology and Rehabilitation, School of Medicine of Ribeirão Preto, University of São Paulo.

*** Head Professor, Department of Morphology, School of Dentistry of Piracicaba, State University of Campinas.
} 
Rodrigues D, Siriani AO, Bérzin F. Effect of conventional TENS on pain and electromyographic activity of masticatory muscles in TMD patients. Braz Oral Res 2004;18(4):290-5.

in the electromyographic signs of masticatory muscles.

According to some studies ${ }^{3,13,17}$, TMD subjects present increased electromyographic (EMG) activity of masticatory muscles with the jaw at rest, i. e., closed lips with no teeth contact, and lower level of clenching electric activation. Some authors ${ }^{11,16,19}$ also reported that, during mastication, subjects with TMD present activity in jaw-closing muscles (masseter and temporal muscles) during the opening phase, when they should be relaxed.

Cooper et al. ${ }^{2}$ (1991) and Lous et al. ${ }^{8}$ (1970) stated that, among the masticatory muscles, the anterior portion of temporal muscles shows the highest electromyographic activity (hyperactivity) when the jaw is at rest position. However, this hyperactivity of masticatory muscles at rest has been widely discussed. Some authors believe it is an exaggeration to consider muscular hyperactivity alterations from 1 to $2 \%$ of the maximum production of electrical activity of a muscle ${ }^{10}$.

Different researches have found different results in myoelectric activity during clenching. Naeije, Hansson ${ }^{12}$ (1986) and Rodrigues ${ }^{15}$ (2000) did not observe statistically significant differences in masticatory muscle EMG activity between control and TMD volunteers.

Many studies have demonstrated the effect of some therapeutic resources that would reduce pain and reestablish function of the masticatory muscles. Under this aspect, transcutaneous electric nerve stimulation (TENS) deserves special attention because it presents no side effects and enables both pain reduction ${ }^{5}$ and alteration in EMG activity ${ }^{16}$.

Works on the effects of TENS on masticatory muscles show that it is an effective resource in the relief of pain and in the decrease of EMG activity of masticatory muscles at rest ${ }^{1,2,6,21}$, in the reduction of myoelectric activity of the jaw-closing muscles during the opening phase of the jaw in TMD patients ${ }^{16}$, and in the increase of muscular electrical activity recorded during clenching in TMD patients ${ }^{1,2}$. On the other hand, recent studies $^{15}$ did not present the same results.

Thus, the objective of the present work was to evaluate the effect of a single TENS application in conventional mode (high-frequency and sensorial threshold) on pain and on the amplitude of masticatory muscle EMG records of TMD patients.

\section{MATERIALS AND METHODS}

Thirty five female volunteers $(n=35)$ participated in this study: nineteen TMD patients, aged 19 to 33 (mean age $=23.04, \mathrm{SD}= \pm 3.5$ years), and sixteen clinically normal subjects aged 19 to 31 (mean age $=23.3, \mathrm{SD}= \pm 3.0$ years). In the TMD group, volunteers presented:

1. pain in the temporal and masseter muscles during functional activities for at least one year and a maximum of 5 years;

2. occlusal parafunction (clenching and/or grinding) for at least one year;

3. pain and/or muscular fatigue when waking up;

4. no functional limitation.

The control group included subjects with no occlusal parafunction, no joint trauma, no joint and/or muscular pain during functional activities, no muscular fatigue and/or pain when waking up. Patients with dental loss, systemic disease which could affect TMJ or cervical joints, e. g. rheumatoid arthritis, osteoarthrosis, osteoporosis, diabetes, and patients taking analgesic, muscle relaxant or anti-inflammatory drugs were excluded, because such drugs could influence the results.

Volunteers were selected after functional evaluation (personal data, anamnesis, background facts, visual inspection, muscular palpation, and functional exam), and dental evaluation, considering oral and dental conditions. All volunteers signed the formal participation form submitted to and approved by the Human Research Ethics Committee, School of Dentistry of Piracicaba, State University of Campinas.

Surface electromyography was recorded at the anterior temporal and masseter muscles using surface differential electrodes of silver bars $10 \mathrm{~mm}$ apart, $10 \mathrm{~mm}$ long, $2 \mathrm{~mm}$ wide, gain of 100 times, input impedance of $10 \mathrm{G} \Omega$ and common mode of rejection ratio (CMRR) of $130 \mathrm{~dB}$ (Lynx Tecnologia Eletrônica Ltda., São Paulo, SP, Brazil). The EMG signals were analogically amplified with gain of $100 \mathrm{X}$, filtered (10-509 $\mathrm{Hz}$ bandpass Butterworth filter, second order filter) and sampled by 12 bits A/D covert board (model CAD 12/46, Lynx Tecnologia Eletrônica Ltda., São Paulo, SP, Brazil) with $1 \mathrm{kHz}$ frequency. The signals were digitally bandpass filtered $(10-500 \mathrm{~Hz})$.

The differential electrodes were placed over both the masseter and the anterior temporal muscles; the position was determined by muscle palpation. A rectangular stainless steel electrode 
Rodrigues D, Siriani AO, Bérzin F. Effect of conventional TENS on pain and electromyographic activity of masticatory muscles in TMD patients. Braz Oral Res 2004;18(4):290-5.

(3 x $4 \mathrm{~cm}$ ) (Bio-logic Systems Corp., Mundelein, IL, Chicago) was also used as a reference electrode to reduce noise acquisition, fixed on the right wrist of the volunteer.

The volunteers remained comfortably sat on a chair with their bodies lined up and their backs at rest (Frankfurt plan parallel to the ground), eyes open, and arms resting on inferior limbs.

Three five-second recordings of the surface electromyography signals were performed during each of the following situations: (1) rest: subject with mandible at rest, teeth separated, and lips together; (2) isometric contraction: subjects clenched their teeth. During clenching, the researcher issued a verbal command for maximum clenching while volunteers clenched Parafilm M (American National Can, Chicago, IL). The material was placed bilaterally between upper and lower teeth, from second premolars to second molars. Previous training was given to familiarize subjects with the experimental procedure. Before the removal of surface electromyography electrodes, marks were drawn on volunteers' skin to indicate where to replace them after electrical stimulation.

Transcutaneous electrical nerve stimulation was delivered by a transcutaneous electrical stimulator (model Dualpex 961, Quark Produtos Médicos, Piracicaba, SP, Brazil) of two channels and four circular self-adhesive percutaneous electrodes measuring $42 \mathrm{~mm}$ (ValuTrode Fallbrook, California, USA). TENS was applied using frequency of $150 \mathrm{~Hz}$; pulse width of $20 \mu \mathrm{s}$; intensity (mA) exclusively set at the subject's sensorial threshold; modulation up to $50 \%$ of variation frequency; quadratic biphasic symmetrical pulse and length of application of 45 minutes.

The volunteers were stimulated in dorsal decubitus, adequately positioned with a roll under their knees. The percutaneous electrodes of electrical stimulation were placed on the masseter and on the anterior portion of the temporal muscle bilaterally. The channels were distributed so that one channel would stimulate the masseter and the other, the temporal, due to their morphological differences and distinct intensity quantities for a given limit of electrical excitability. After the period of application of the electrical stimulation, recording electrodes were repositioned and the EMG signal was recorded as described previously.

Pain evaluation was performed using a visual analogue scale (VAS), which was applied before and immediately after electrical stimulation in both studied groups through different recording forms, so that subjects could not observe what had been written before the application. The intensity of pain was recorded in centimeters, measured from the beginning of the scale (no pain) to the point established by the volunteer. These data showed regular distribution and were compared using Student's $t$-test, at 5\% significance level for the values before and after the application of electrical stimulation only for the TMD group. The value obtained in the scale for the control group was zero, that is, they did not present pain before or after the application.

The masseter and the anterior portion of the temporal muscle EMG amplitudes were analyzed bilaterally by root mean square (RMS) values. The RMS values at rest and at clenching obtained before and after TENS application were analyzed using paired Student's $t$-test. RMS values of the experimental groups were also compared using Student's $t$-test. For all analyses, the values $\mathrm{p} \leq 0.05$ and $\mathrm{p} \leq 0.01$ were considered significant and highly significant, respectively.

\section{RESULTS}

\section{Pain intensity - VAS mean values}

The TENS application promoted significant $(p=0.001)$ pain relief just for the TMD group (Table 1).

\section{EMG amplitude - RMS values}

The RMS values of both groups recorded with the jaw at rest before TENS are shown in Table 2. It can be observed that EMG activity at rest is higher in the TMD group than in the control one $(\mathrm{p} \leq 0.05)$.

The comparison of RMS values of the TMD group recorded with the jaw at rest before and after TENS are shown in Table 3. It can be observed that after TENS there was a significant decrease $(p \leq 0.05)$ in EMG activity of the anterior portion

TABLE 1 - Mean values and standard deviation of the VAS in the TMD group $(n=19)$ before and after TENS application. Values in $\mathrm{cm}$.

\begin{tabular}{c|c|c}
\hline \hline \multirow{2}{*}{} & \multicolumn{2}{|c}{ TENS treatment } \\
\cline { 2 - 3 } & Before TENS & After TENS \\
\hline Pain intensity & $5.75 \pm 1.41$ & $1.32 \pm 1.05^{*}$ \\
\hline \hline
\end{tabular}

*Significance $(\mathrm{p}=0.001)$ based on paired $t$ test for before and after treatment. VAS: visual analogue scale. TENS: transcutaneous electrical nerve stimulation. TMD: Temporomandibular disorders. 
Rodrigues D, Siriani AO, Bérzin F. Effect of conventional TENS on pain and electromyographic activity of masticatory muscles in TMD patients. Braz Oral Res 2004;18(4):290-5.

TABLE 2 - Mean values and standard deviation (SD) of EMG activity recorded with the jaw at rest in TMD (n = 19) and control $(\mathrm{n}=16)$ groups before TENS application. Values in $\mu$ volts.

\begin{tabular}{l|c|c|c|c}
\hline \hline \multirow{2}{*}{ TMD group } & \multicolumn{4}{|c}{ Muscles } \\
\cline { 2 - 5 } & RT (Mean/SD) & RM (Mean/SD) & LT (Mean/SD) & LM (Mean/SD) \\
\hline Control group & $6.37 \pm 2.43$ & $3.29 \pm 1.19$ & $6.83 \pm 3.34$ & $3.36 \pm 1.26$ \\
\hline p value & $2.47 \pm 0.56$ & $2.39 \pm 0.55$ & $2.74 \pm 0.64$ & $2.67 \pm 0.71$ \\
\hline \hline
\end{tabular}

RT and LT: anterior portion of the right and left temporal muscles. RM and LM: right and left masseters. EMG activity: electromyographic activity. TENS: transcutaneous electrical nerve stimulation. TMD: temporomandibular disorders.

TABLE 3 - Mean values and standard deviation (SD) of EMG activity recorded with the jaw at rest in the TMD group $(\mathrm{n}=19)$ before and after TENS application. Values in $\mu$ volts.

\begin{tabular}{l|c|c|c|c}
\hline \hline \multirow{2}{*}{ Before TENS } & \multicolumn{4}{|c}{ Muscles } \\
\cline { 2 - 5 } & RT (Mean/SD) & RM (Mean/SD) & LT (Mean/SD) & LM (Mean/SD) \\
\hline After TENS & $6.37 \pm 2.43$ & $3.29 \pm 1.19$ & $6.83 \pm 3.34$ & $3.36 \pm 1.26$ \\
\hline p value & $4.73 \pm 1.89$ & $2.91 \pm 1.03$ & $5.06 \pm 2.05$ & $3.16 \pm 1.18$ \\
\hline \hline
\end{tabular}

RT and LT: anterior portion of the right and left temporal muscles. RM and LM: right and left masseters. EMG activity: electromyographic activity. TENS: transcutaneous electrical nerve stimulation. TMD: temporomandibular disorders.

TABLE 4 - Mean values and standard deviation (SD) of EMG activity recorded during clenching in TMD $(\mathrm{n}=19)$ and control $(n=16)$ groups before TENS application. Values in $\mu$ volts.

\begin{tabular}{l|c|c|c|c}
\hline \hline \multirow{2}{*}{ TMD group } & \multicolumn{4}{|c}{ Muscles } \\
\cline { 2 - 6 } & RT (Mean/SD) & RM (Mean/SD) & LT (Mean/SD) & LM (Mean/SD) \\
\hline Control group & $116.37 \pm 31.58$ & $145.79 \pm 39.34$ & $157.58 \pm 41.15$ & $158.99 \pm 34.48$ \\
\hline p value & $123.66 \pm 34.99$ & $168.16 \pm 69.62$ & $167.48 \pm 50.39$ & $167.55 \pm 50.52$ \\
\hline \hline
\end{tabular}

RT and LT: anterior portion of the right and left temporal muscles. RM and LM: right and left masseters. EMG activity: electromyographic activity. TENS: transcutaneous electrical nerve stimulation. TMD: temporomandibular disorders.

TABLE 5 - Mean values and standard deviation (SD) of EMG activity recorded during clenching in the TMD group $(\mathrm{n}=19)$ before and after TENS application. Values in $\mu$ volts.

\begin{tabular}{l|c|c|c|c}
\hline \hline \multirow{2}{*}{ Before TENS } & \multicolumn{4}{|c}{ Muscles } \\
\cline { 2 - 5 } & RT (Mean/SD) & RM (Mean/SD) & LT (Mean/SD) & LM (Mean/SD) \\
\hline After TENS & $116.37 \pm 31.58$ & $145.79 \pm 39.34$ & $157.58 \pm 41.15$ & $158.99 \pm 34.48$ \\
\hline $\mathrm{p}$ value & $115.68 \pm 31.10$ & $190.68 \pm 48.05$ & $161.07 \pm 46.32$ & $171.07 \pm 46.32$ \\
\hline \hline
\end{tabular}

RT and LT: anterior portion of the right and left temporal muscles. RM and LM: right and left masseters. EMG activity: electromyographic activity. TENS: transcutaneous electrical nerve stimulation. TMD: temporomandibular disorders.

of the temporal muscle bilaterally in the group with TMD, whereas no significant difference was observed for the right and left masseter muscles.

The RMS values of the control and TMD groups recorded during clenching before the TENS application are shown in Table 4 . There is no signifi- cant difference between TMD and control groups $(\mathrm{p}>0.05)$.

The comparison of clenching RMS values of the TMD group before and after TENS is shown in Table 5. It can be seen that after TENS there was significant increase in the EMG activity of the masseter muscles in the TMD group, whereas no 
Rodrigues D, Siriani AO, Bérzin F. Effect of conventional TENS on pain and electromyographic activity of masticatory muscles in TMD patients. Braz Oral Res 2004;18(4):290-5.

significant difference was observed for the anterior portion of the temporal muscle.

\section{DISCUSSION}

The results of this study showed that, at rest, TMD subjects show higher myoelectric activity of the jaw elevator muscles than the control group. This is more evident in the anterior portion of the temporal muscle. No significant differences were observed between the evaluated groups during clenching. We could also observe that TENS promoted pain relief with concurrent reduction in myoelectric activity in the anterior portion of the temporal muscle at rest, and an increase of that activity in the masseter muscles during clenching in the experimental groups.

Several authors reported that TMD subjects present hyperactivity of the masticatory muscles with the jaw at rest and this may cause ische mia, muscular fatigue, and pain ${ }^{7,14,22}$. Lund et al. ${ }^{9}$ (1991), Lund, Sessle ${ }^{10}$ (2000) and Stohler et al. ${ }^{20}$ (1996) criticize the use of the word "hyperactivity" meaning increased activity in the masticatory muscles with the jaw at rest in TMD subjects. According to Lund, Sessle ${ }^{10}$ (2000), the so-called muscular resting "hyperactivity" of the jaw elevator muscles ranges from 1 to $2 \%$ of the maximum activity recorded using electromyography during maximum voluntary clenching.

According to the authors mentioned above, the word "hyperactivity" at rest is not adequate. To receive this denomination, the activity records should contain values between 9 and $10 \%$ of the maximum activity recorded during maximum voluntary clenching, period during which, according to Finsterer ${ }^{4}$ (2001), we can identify the typical interference pattern of the surface electromyographic record.

On the other hand, the results obtained in this work and in clinical experience show that alterations in electromyographic signals of TMD subjects must be considered. Although more studies are necessary in order to determine their causes, the increase in electromyographic amplitude of the jaw elevator muscles at rest is probably due to sensorial-motor interactions, of which pain, a symptom present in most TMD subjects evaluated, can modify the generation of action potentials and, finally, the amplitude of myoelectric activity.

The temporal muscle, among the jaw elevators, is where manifestations of increased electromyographic activity were more frequently reported in cases of temporomandibular disorder. Data of the present work are in agreement with this finding and are in accordance with Lous et al. ${ }^{8}$ (1970) and Cooper et al. ${ }^{2}$ (1991).

The reduction in myoelectric activity of the jaw elevator muscles in records with mandibular rest as a result of TENS, as observed in the present study, was previously described by other authors ${ }^{1,2,6,21}$ studying TMD subjects as well.

It should be pointed out that only the anterior portion of the left and right temporal muscles presented significant reduction of electromyographic activity, showing that TENS did not cause the same result for all studied muscles. These data are in accordance with the findings of Kamyszek et al. ${ }^{6}$ (2001), who, through the use of 30- to 40minute ultralow frequency stimulation, observed a reduction in electromyographic activity at rest, but a non-homogenous effect in the masticatory muscles studied.

On the other hand, data from the present work disagree with the findings of Cooper et al. ${ }^{2}$ (1991), who, as a result of a 60- to 90-minute low frequency TENS application, obtained uniform effect in the decrease of electromyographic activity at rest and increase of that activity during isometric contraction of the jaw elevator muscles.

We believe that to obtain the same TENS effect in all the studied muscles, both at rest and during clenching, further studies are necessary with variation in the stimulation frequency for a period of over 45 minutes, in order to determine the influence of these variables in the observed results.

As to clenching, the results of the present work showed that there was no significant difference between RMS values of the control and TMD groups.

Data from the present work are in agreement with the findings of Naeije, Hansson ${ }^{12}$ (1986), who did not find significant differences in electromyographic activity recorded during isometric contraction of subjects clinically normal or with pathological conditions. However, our data differ from those of Sheikholeslam et al. ${ }^{18}$ (1980), who evaluated the masseter muscles and the anterior portion of the temporal muscle of 39 TMD subjects, aged 14 to 70 , and of 45 non-TMD subjects, aged 20 to 32, by surface electromyography. As to the symptoms, TMD subjects presented pain in the masticatory muscles, sensitivity to touch in the temporomandibular joint, and limited opening width.

Possibly, the subjects evaluated by Sheikholeslam et al. ${ }^{18}$ (1980) had joint complications 
Rodrigues D, Siriani AO, Bérzin F. Effect of conventional TENS on pain and electromyographic activity of masticatory muscles in TMD patients. Braz Oral Res 2004;18(4):290-5.

and, according to Naeije, Hansson ${ }^{12}$ (1986), subjects with arthrogenic disorders show lower electromyographic activity than myogenic temporomandibular disorder subjects.

Lund et al. ${ }^{9}$ (1991) reported that, in situations of chronic muscular pain, muscular contraction ability is reduced due to the decrease in activity of the agonist muscles and the increase in activity of the antagonist muscles. The results of this work disagree with the statements regarding no significant difference observed in clenching myoelectric activity of the jaw elevator muscles compared with the control group. Besides, the suprahyoid muscles, which are antagonistic to the temporal and masseter muscles, were not evaluated.

As to clenching electromyographic activity, we can see that the related literature is controversial. Some authors reported decrease in the electromyographic activity in pain and others did not. Thus, future studies should use samples with

\section{REFERENCES}

1. Cooper BC. The role of bioelectronic instrumentation in the documentation and management of temporomandibular disorders. Oral Surg Oral Med Oral Pathol Oral Radiol Endod 1997;83:91-100.

2. Cooper BC, Cooper DL, Lucente FE. Electromyography of masticatory muscles in craniomandibular disorders. Laryngoscope 1991;101:150-7.

3. Dahlström L. Electromyographic studies of craniomandibular disorders: a review of the literature. J Oral Rehabil 1989;16:1-20.

4. Finsterer J. EMG-interference pattern analysis. J Electromyogr Kinesiol 2001;11:231-46.

5. Johnson MI, Ashton CH, Thompson JW. The clinical use of TENS. J Orthop Med 1992;14:3-12.

6. Kamyszek G, Ketcham R, Garcia R Jr, Radke J. Electromyographic evidence of reduced muscle activity when ULFTENS is applied to the $\mathrm{V}^{\text {th }}$ and VII ${ }^{\text {th }}$ cranial nerves. Cranio 2001;19:162-8.

7. Laskin DM. Etiology of the pain-dysfunction syndrome. J Am Dent Assoc 1969;79:147-53.

8. Lous I, Sheikholeslam A, Moller E. Postural activity in subjects with functional disorders of the chewing apparatus. Scand J Dent Res 1970;78:404-10.

9. Lund JP, Donga R, Widmer CG, Stohler CS. The pain-adaptation model: a discussion of the relationship between chronic musculoskeletal pain and motor activity. Can J Physiol Pharmacol 1991;69:683-94.

10. Lund JP, Sessle BJ. Mecanismos neurofisiológicos. In: Zarb GA, Carlsson GE, Sessle BJ, Mohl ND. Disfunções da articulação temporomandibular e dos músculos da mastigação. $2^{a}$ ed. São Paulo: Santos; 2000. p. 188-207.

11. Moller E, Sheikholeslam A, Lous I. Response of elevator activity during mastication to treatment of functional disorders. Scand J Dent Res 1984;92:64-83.

12. Naeije M, Hansson TL. Electromyographic screening of myogenous and arthrogenous TMJ dysfunction patients. J Oral Rehabil 1986;13:433-41. similar disorders as well as the records of the jaw depressor muscles.

\section{CONCLUSION}

In the conditions of this experiment, it was assumed that TMD subjects present higher electromyographic activity with the jaw at rest than clinically normal subjects, and that such situation is not defined as a causal factor of temporomandibular disorders, but as one of the symptoms of the syndrome. A single conventional TENS application for 45 minutes is efficacious for the relief of pain. However, in general, it does not provide the same effect on the electromyographic activity of the studied muscles, which were recorded both at rest and during isometric contraction. Thus, further studies with longer application and/or different stimulation frequencies are necessary.

13. Pinho JC, Caldas FM, Mora MJ, Santana-Penin U. Electromyographic activity in patients with temporomandibular disorders. J Oral Rehabil 2000;27:985-90.

14. Ramfjord SP. Bruxism, a clinical and electromyographic study. J Am Dent Assoc 1961;62:21-44.

15. Rodrigues D. Efeito da estimulação elétrica nervosa transcutânea na atividade elétrica do $\mathrm{m}$. masseter e da porção anterior do $\mathrm{m}$. temporal em indivíduos portadores de desordem craniomandibular - análise eletromiográfica [Dissertação de Mestrado]. São Carlos: Universidade Federal de São Carlos; 2000.

16. Rodrigues D, Oliveira AS, Bérzin F. Effect of TENS on the activation pattern of the masticatory muscles in TMD patients. Braz J Oral Sci 2004;3:510-5.

17. Schroeder H, Siegmund H, Santibanez G, Kluge A. Causes and signs of temporomandibular joint pain and dysfunction: an electromyographical investigation. J Oral Rehabil 1991;18:301-10.

18. Sheikholeslam A, Moller E, Lous I. Pain, tenderness and strength of human mandibular elevators. Scand J Dent Res 1980;88:60-6.

19. Stohler CS, Ashton-Miller JA, Carlson DS. The effects of pain from the mandibular joint and muscles on masticatory motor behaviour in man. Arch Oral Biol 1988;33:175-82.

20. Stohler CS, Zhang X, Lund JP. The effect of experimental jaw muscle pain on postural muscle activity. Pain 1996;66:215-21.

21. Treacy K. Awareness/relaxation training and transcutaneous electrical neural stimulation in the treatment of bruxism. J Oral Rehabil 1999;26:280-7.

22. Ueda HM, Kato M, Saifuddin M, Tabe H, Yamaguchi $\mathrm{K}$, Tanne K. Differences in the fatigue of masticatory and neck muscles between male and female. J Oral Rehabil 2002;29:575-82.

Received for publication on Jun 23, 2004

Sent for alterations on Oct 08, 2004

Accepted for publication on Nov 23, 2004 